\title{
Article \\ Organic Nanoparticles Based on D-A-D Small Molecule: Self-Assembly, Photophysical Properties, and Synergistic Photodynamic/Photothermal Effects
}

\author{
Liangliang Yue ${ }^{1,2} \mathbb{D}$, Haolan $\mathrm{Li}^{1}$, Qi Sun ${ }^{3}$, Xiaogang Luo ${ }^{1,4}$, Fengshou Wu ${ }^{1, *}$ and Xunjin Zhu ${ }^{2, * \mathbb{D}}$ \\ 1 Hubei Key Laboratory of Novel Reactor and Green Chemical Technology, Key Laboratory for Green Chemical \\ Process of the Ministry of Education, School of Chemical Engineering and Pharmacy, Wuhan Institute of \\ Technology, Wuhan 430205, China; yuel1994@163.com (L.Y.); lh1970816@163.com (H.L.); \\ xgluo@wit.edu.cn (X.L.) \\ 2 Department of Chemistry, Hong Kong Baptist University, Waterloo Road, Hong Kong, China \\ 3 School of Chemistry and Environmental Engineering, Wuhan Institute of Technology, Wuhan 430205, China; \\ qisun@wit.edu.cn \\ 4 School of Materials Science and Engineering, Zhengzhou University, Zhengzhou 450001, China \\ * Correspondence: fswu@wit.edu.cn (F.W.); xjzhu@hkbu.edu.hk (X.Z.)
}

\section{check for}

updates

Citation: Yue, L.; Li, H.; Sun, Q.; Luo,

X.; Wu, F.; Zhu, X. Organic

Nanoparticles Based on D-A-D Small Molecule: Self-Assembly,

Photophysical Properties, and

Synergistic Photodynamic/

Photothermal Effects. Materials 2022,

15, 502. https://doi.org/10.3390/

ma15020502

Academic Editor: Montserrat

Colilla

Received: 15 November 2021

Accepted: 4 January 2022

Published: 10 January 2022

Publisher's Note: MDPI stays neutral with regard to jurisdictional claims in published maps and institutional affiliations.

Copyright: (c) 2022 by the authors. Licensee MDPI, Basel, Switzerland. This article is an open access article distributed under the terms and conditions of the Creative Commons Attribution (CC BY) license (https:/ / creativecommons.org/licenses/by/ $4.0 /)$.

\begin{abstract}
Cancer is one of the major diseases threatening human health. Traditional cancer treatments have notable side-effects as they can damage the immune system. Recently, phototherapy, as a potential strategy for clinical cancer therapy, has received wide attention due to its minimal invasiveness and high efficiency. Herein, a small organic molecule (PTA) with a D-A-D structure was prepared via a Sonogashira coupling reaction between the electron-withdrawing dibromo-perylenediimide and electron-donating 4-ethynyl- $N, N$-diphenylaniline. The amphiphilic organic molecule was then transformed into nanoparticles (PTA-NPs) through the self-assembling method. Upon laser irradiation at $635 \mathrm{~nm}$, PTA-NPs displayed a high photothermal conversion efficiency (PCE $=43 \%$ ) together with efficient reactive oxygen species (ROS) generation. The fluorescence images also indicated the production of ROS in cancer cells with PTA-NPs. In addition, the biocompatibility and photocytotoxicity of PTA-NPs were evaluated by 3-(4,5-Dimethylthiazol-2-yl)-2,5-diphenyltetrazolium bromide (MTT) assay and live/dead cell co-staining test. Therefore, the as-prepared organic nanomaterials were demonstrated as promising nanomaterials for cancer phototherapy in the clinic.
\end{abstract}

Keywords: perylene diimide; self-assembly; organic nanomaterials; photothermal therapy; reactive oxygen species

\section{Introduction}

Because of its high mortality, cancer has always been a great threat to human health [1]. Today, a considerable number of traditional cancer treatments exist. However, most of these conventional cancer treatments cause irreversible side-effects to healthy cells in clinical application [2,3]. During the last decade, much effort has been dedicated to explore new cancer treatment methods with low side-effects [4,5] Photodynamic therapy (PDT) and photothermal therapy (PTT) showed the advantages of minimal invasiveness and high therapeutic efficiency, thus attracting much attention as a promising therapeutic technique [6-9]. In PDT, the light irradiation of photosensitizers produces reactive oxygen species (ROS) which can abolish cancer cells and tissue $[10,11]$. PTT mainly depends on the local heat effect induced by near-infrared light irradiation on photothermal agents, resulting in the damage of tumor cells [12,13].

Based on the mechanism of PDT and PTT, much effort has been dedicated to developing photosensitizers with high ROS generation or efficient photothermal conversion efficiency (PCE) for effective cancer phototherapy. Up to now, a great number of photosensitizers including organic and inorganic functional materials have been designed 
and studied for PTT and PDT, such as noble metal nanoparticles [14], metal chalcogenide nanomaterials [15], carbon-based nanomaterials [16], magnetic nanoparticles [17], and polymer materials [18]. Although inorganic materials generally exhibit high photothermal conversion efficiency or efficient ROS generation due to their semiconductor properties, they are limited in clinic application by their long-term toxicity toward organisms. Recently, organic materials with excellent biocompatibility have gained considerable interest for PTT or PDT applications, such as porphyrin [19,20], phthalocyanine [21,22], and diketopyrrolopyrrole $[23,24]$. In 2017, Dong et al. synthesized organic NPs from an organic molecule, which was constructed by conjugating triphenylamine (TPA) with 3,6-di(2thienyl)-2,5-dihydropyrrolo[3,4-c]pyrrole-1,4-dione (DPP). The prepared organic materials showed efficient singlet oxygen $\left({ }^{1} \mathrm{O}_{2}\right)$ generation $\left(\Phi_{\Delta}=33.6 \%\right)$ and high PCE $(34.5 \%)$ under $660 \mathrm{~nm}$ laser irradiation [25]. Yoon et al. developed phthalocyanine-based nanomaterials (NanoPcTBs) with both photothermal and photoacoustic properties [26]. In recent years, our group also developed a series of small molecule-based nanomaterials with strong absorption in the near-infrared region, which could act as efficient nanoagents in photodynamic or photothermal therapy $[8,19,22]$.

Perylene diimide (PDI) derivatives have been widely studied for phototherapy for their high thermal stability, large $\pi-\pi$ conjugated system, good photochemical properties, and bright luminescence. However, the absence of near-infrared (NIR) absorption and the extreme hydrophobic properties of PDI molecules inhibit their practical application in PTT $[27,28]$. Herein, we designed and synthesized a small organic molecule PTA with a D-A-D structure, where perylene diimide was used as an electronic accepter while triphenylamine was used as an electronic donor. The two components were conjugated through a triple bond, which enhanced the $\pi$ conjugation of the system, leading to a red shift of the absorption spectrum [29]. In order to enhance its water solubility, polyethylene glycol chains were introduced onto the perylene diimide unit. The amphiphilic PTA was then self-assembled into the related nanostructures (PTA-NPs) through the nanoprecipitation method [30]. PTA-NPs exhibited high photothermal conversion efficiency (PCE = 43\%) under $635 \mathrm{~nm}$ laser, which was comparable to that of reported organic nanomaterials (Table 1). The photocytotoxicity and intracellular ROS generation of PTA-NPs were finally verified by MTT assay and fluorescence images. Compared to those reported nanomaterials, the PTA-NPs showed several distinct properties, including (1) organic nanomaterials generated from small molecules (PTA) with a clear structure and accurately determined molecular weight, (2) high photothermal conversion efficiency (43\%), and (3) simple fabrication method without the addition of any other reagents. Therefore, PTA-NPs are very promising for photothermal cancer therapy in preclinical applications.

Table 1. Comparison of different organic nanomaterials for PTT.

\begin{tabular}{clcccc}
\hline Nanomaterials & Type & Size & $\begin{array}{c}\text { Absorption } \\
\left(\boldsymbol{\lambda}_{\max }\right)\end{array}$ & PCE & Reference \\
\hline PDI-NPs & Small molecule & $55 \mathrm{~nm}$ & $630 \mathrm{~nm}$ & $43 \%$ & {$[31]$} \\
\hline ZnP2 NPs & Small molecule & $120 \mathrm{~nm}$ & $668 \mathrm{~nm}$ & $33.4 \%$ & {$[32]$} \\
\hline BAF4 NPs & Small molecule & $79 \mathrm{~nm}$ & $1000 \mathrm{~nm}$ & $80 \%$ & {$[33]$} \\
\hline NDTB NPs & Small molecule & $110 \mathrm{~nm}$ & $1050 \mathrm{~nm}$ & $40.6 \%$ & {$[34]$} \\
\hline PTA-NPs & Small molecule & $200 \mathrm{~nm}$ & $800 \mathrm{~nm}$ & $43 \%$ & This work \\
\hline
\end{tabular}

\section{Experimental Sections}

\subsection{Synthesis}

N,N-Bis[2-(2-(2-Ethoxyethoxy)ethoxy)ethylane]-1,7-dibromoperylene-3,4,9,10-tetracarboxylic acid bisimide (10) [35], 4-bromo- $N, N$-diphenyl aniline (6) [36], and 4-ethynyl- $N, N$-diphenylaniline (7) [37] were prepared according to methods in the literature (Scheme S1). 
$\mathrm{N}, \mathrm{N}$-Bis[2-(2-(2-ethoxyethoxy)ethoxy)ethylane]-1,7-di(4-ethynyl- $\mathrm{N}, \mathrm{N}$-diphenyl aniline)3,4,9,10-tetracarboxylic acid bisimide (PTA) [38].

A two-necked round-bottom flask was filled with Compound $10(20.00 \mathrm{mg}, 0.023 \mathrm{mmol})$ THF (10 mL), triethylamine (TEA) $(8 \mathrm{~mL}), \mathrm{CuI}(0.8 \mathrm{mg}, 0.0042 \mathrm{mmol})$, and $\mathrm{PdCl}_{2}\left(\mathrm{PPh}_{3}\right)_{2}$ ( $3 \mathrm{mg}, 0.0042 \mathrm{mmol}$ ) under an $\mathrm{N}_{2}$ atmosphere. After the temperature was increased to $50{ }^{\circ} \mathrm{C}$, Compound $7(23.52 \mathrm{mg}, 0.069 \mathrm{mmol})$ was added to the system slowly and then heated and kept at $70{ }^{\circ} \mathrm{C}$ for $6 \mathrm{~h}$. The residue was obtained by solvent evaporation and then purified through column (silica gel) chromatography (DCM: $\mathrm{CH}_{3} \mathrm{OH}=45: 1$ ) to afford the desired product as a purple-black solid $(17.18 \mathrm{mg}, 60 \%) .{ }^{1} \mathrm{H}-\mathrm{NMR}\left(400 \mathrm{MHz}, \mathrm{CDCl}_{3}\right) \delta$ $9.91(\mathrm{~d}, J=8.0 \mathrm{~Hz}, 2 \mathrm{H}), 8.65(\mathrm{~s}, 2 \mathrm{H}), 8.47(\mathrm{~d}, J=8.4 \mathrm{~Hz}, 2 \mathrm{H}), 7.42(\mathrm{~d}, J=8.3 \mathrm{~Hz}, 4 \mathrm{H}), 7.33$ $(\mathrm{t}, J=7.5 \mathrm{~Hz}, 8 \mathrm{H}), 7.20-7.10(\mathrm{~m}, 12 \mathrm{H}), 7.05(\mathrm{~d}, J=8.4 \mathrm{~Hz}, 4 \mathrm{H}), 4.45(\mathrm{~s}, 4 \mathrm{H}), 3.84(\mathrm{~s}, 4 \mathrm{H})$, $3.75-3.39(\mathrm{~m}, 20 \mathrm{H}), 1.13(\mathrm{t}, J=6.9 \mathrm{~Hz}, 6 \mathrm{H}) \mathrm{ppm}$. ESI-MS: $m / z$ calculated for $\mathrm{C}_{80} \mathrm{H}_{68} \mathrm{~N}_{4} \mathrm{O}_{10}$ $[\mathrm{M}+\mathrm{H}]^{+}$1244.5, found 1244.5.

\subsection{Preparation of Perylene Diimide-Based Nanoparticles}

The solution of PTA ( $2 \mathrm{mg}$ ) in THF ( $1 \mathrm{~mL}$ ) was added dropwise to $5 \mathrm{~mL}$ of distilled water under continuous sonication (KQ5200B Ultrasonic machine from Kunshan Chaosheng Instrument Limited company, Suzhou, China). After $10 \mathrm{~min}$, the organic solvent was removed by bubbling with nitrogen to obtain PTA-NPs as a homogeneous blue solution. The concentration of PTA-NPs was calculated using a standard curve of the UV/Vis absorbance of PTA [39].

\subsection{Measurement of PCE}

The PCE ( $\eta$ ) of the PTA-NPs was calculated according to Equation (1).

$$
\eta=\frac{h A\left(T_{\max }-T_{\text {surr }}\right)-Q_{\text {Dis }}}{I\left(1-10^{-A 635}\right)}
$$

where $T_{\max }\left({ }^{\circ} \mathrm{C}\right)$ and $T_{\text {surr }}\left({ }^{\circ} \mathrm{C}\right)$ are the real-time temperature and surrounding temperature, respectively. A635 refers to the absorbance of the PTA-NP solution at $635 \mathrm{~nm}\left(1.25 \mathrm{~W} / \mathrm{cm}^{2}\right)$ under the experimental concentration. The value of $h A$ was derived from Equation (2) [40].

$$
\tau_{s}=\frac{m_{D} C_{D}}{h A},
$$

where $\tau_{s}$ is the time constant for heat transfer of the system, which was determined according to the Equations (3) and (4).

$$
\begin{gathered}
T=-\tau_{s} \ln (\theta) . \\
\theta=\frac{T-T_{\text {surr }}}{T_{\text {max }}-T_{\text {surr }} .}
\end{gathered}
$$

In Equation (2), $m_{D}$ and $C_{D}$ are the mass $(3.0 \mathrm{~g})$ and heat capacity $\left(4.2 \mathrm{~J} \cdot \mathrm{g}^{-1}\right)$ of the PBS (phosphate-buffered saline) used to disperse the NPs. In Equation (1), $Q_{D i s}$ represents the heat dissipation from the light absorbed by the water and the quartz sample cell. $Q_{D i s}$ was calculated according to Equation (5).

$$
Q_{\text {Dis }}=\frac{m_{D} C_{D}\left(T_{\max (\text { water })}-T_{\text {surr }}\right)}{\tau_{s}},
$$

where $T_{\max (\text { water })}=35.9{ }^{\circ} \mathrm{C}$ (measured by thermal imager), $T_{\text {surr }}=26.9^{\circ} \mathrm{C}$, and $\tau_{s(\text { water })}=667.14$.

\subsection{Detection of Reactive Oxygen Species (ROS) Generation}

To detect ROS generation with PTA-NPs, the nonfluorescent dichlorodihydrofluorescein $(\mathrm{DCFH})$ was used as a probe, which can be converted to the highly fluorescent 
$2^{\prime}, 7^{\prime}$-dichlorofluorescein (DCF) in the presence of PTA-NPs under $635 \mathrm{~nm}$ laser irradiation. The fluorescence emission spectra of the DCF solution were measured within 500-588 nm upon excitation at $488 \mathrm{~nm}$. The intracellular ROS generation was detected using the same method with dichlorodihydrofluorescein diacetate (DCFH-DA) as a probe. Specifically, the cancer cells were cultivated with DCFH-DA for $4 \mathrm{~h}$ and treated with PTA-NP solution. After laser irradiation at $635 \mathrm{~nm}$ for $5 \mathrm{~min}$, the fluorescence images of cancer cells were observed by fluorescence microscopy (Zeiss, Oberkochen, Germany) [41].

\subsection{Cytotoxicity Assay of PTA-NPs}

First, $200 \mu \mathrm{L}$ of PTA-NP solutions with different concentrations $(0,1,5,10,15$, and $20 \mu \mathrm{g} / \mathrm{mL})$ were added into the plates where A549 cells $\left(6 \times 10^{3}\right.$ cells per well) were cultivated. After incubation for $4 \mathrm{~h}$, half of the A549 cells in the presence of PTA-NPs were irradiated with a $635 \mathrm{~nm}$ laser $\left(1.5 \mathrm{~W} / \mathrm{cm}^{2}\right)$ for $3 \mathrm{~min}$, and the other half were kept in the dark. All cancer cells were cultivated for another $5 \mathrm{~h}$, treated with MTT solution at $37^{\circ} \mathrm{C}$ for $4 \mathrm{~h}$ in $5 \% \mathrm{CO}_{2}$, and then measured by a microplate reader at $570 \mathrm{~nm}$. For the co-staining study, the cancer cells were cultivated with calcein AM and PI for $4 \mathrm{~h}$ and treated with PBS only, laser only, PTA-NPs only, or PTA-NPs + laser [42].

\section{Results and Discussion}

\subsection{Synthesis of PTA and PTA-NPs}

The synthetic procedures of PTA molecule and PTA-NPs are shown in Schemes 1 and S1 (see Supplementary Materials). PTA with a D-A-D structure was synthesized through a Sonigashira coupling reaction with electron donor TPA and perylene diimide as the starting materials. The amphiphilic organic molecule was then self-assembled into the nanoparticles (PTA-NPs) by the reprecipitation method. The structure of the target molecule was confirmed by mass and NMR spectra (see Supplementary Materials Figures S1-S6).

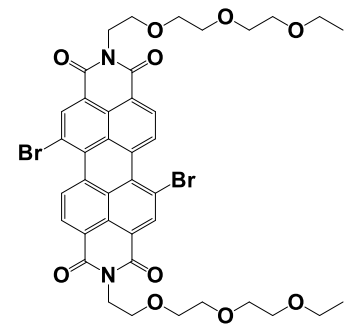

10
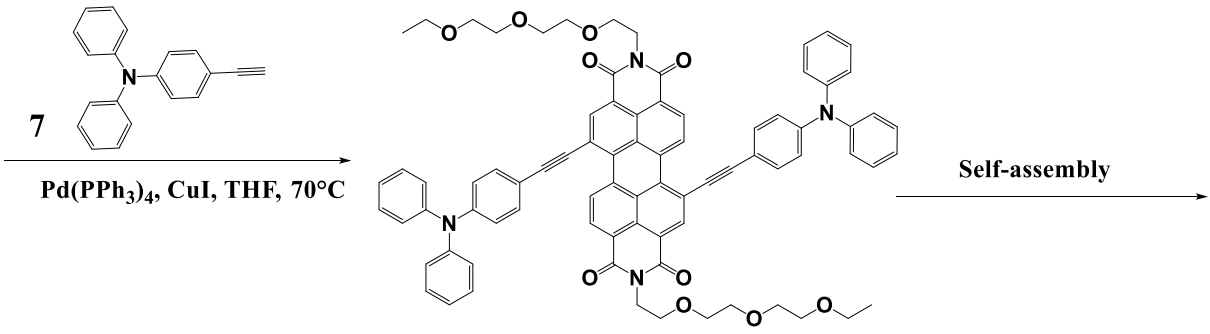

PTA

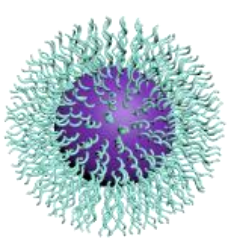

PTA-NPs

Scheme 1. The synthetic routes of PTA and PTA-NPs.

\subsection{Morphology and Particle Size}

The morphology of PTA-NPs was studied by transmission electron microscopy (TEM), and the particle size was determined by dynamic light scattering (DLS). As shown in Figure 1A, a spherical morphology was observed for PTA-NPs with an average diameter around $200 \mathrm{~nm}$, which was helpful for the accumulation of nanoparticles at the tumor site through the enhanced permeability and retention (EPR) effect. In addition, the DLS analysis further confirmed the uniform dispersion of PTA-NPs in PBS solution with an average size of $200 \mathrm{~nm}$ (Figure 1B). The zeta potential ( () of PTA-NPs was $-10 \mathrm{mV}$, indicating the good stability of the aqueous solution (Figure 1C). 

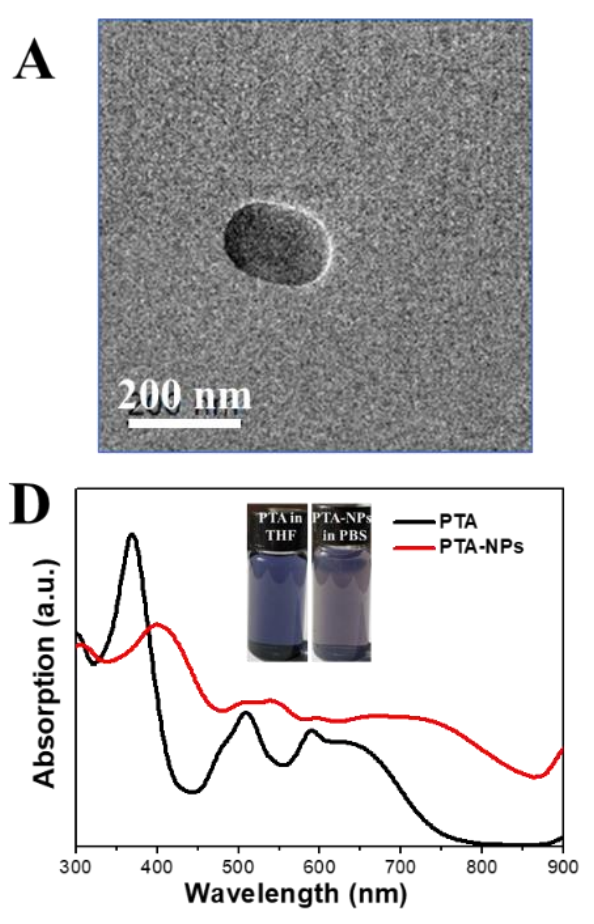
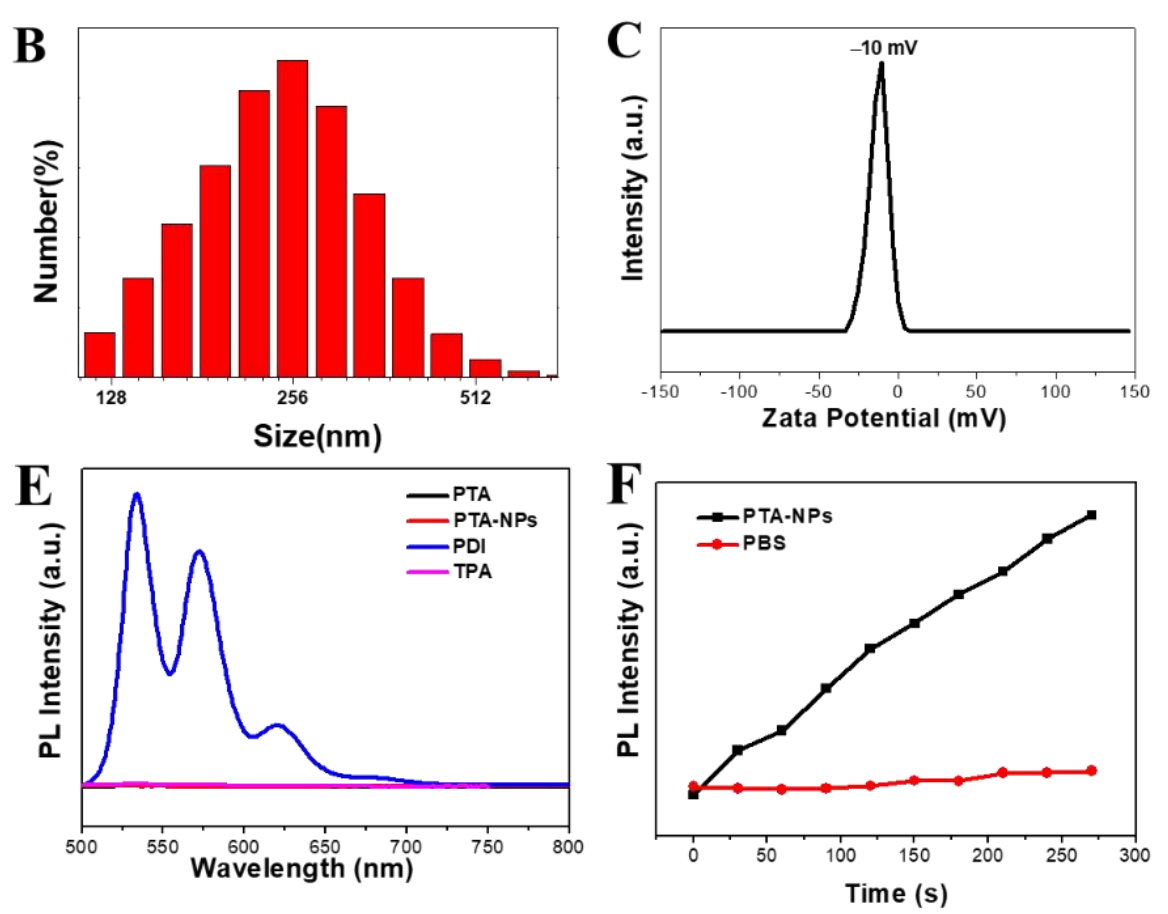

Figure 1. (A) TEM image of PTA-NPs; (B) DLS size profiles of PTA-NPs; (C) zeta potential of PTANPs; (D) UV/Vis absorption spectra of PTA and PTA-NPs (insert: the photographs of PTA in THF and PTA-NPs in PBS); (E) fluorescence spectra of PTA, PDI, TPA, and PTA-NPs; (F) changes in photoluminescence (PL) intensity of the characteristic peak of DCF (525 nm) with irradiation time.

\subsection{Photophysical Properties}

As shown in Figure 1D, PTA exhibited a broad absorption spectrum in the UV/visible and near-infrared region (NIR) due to the large conjugated system. After self-assembly into PTA-NPs, the absorption spectrum was red-shifted and broadened to some extent, with a maximum absorption peak extension to $800 \mathrm{~nm}$, probably ascribed to the $\pi-\pi$ stacking of the conjugated structure in the nanoparticles. PTA-NPs were dispersed very well in water and did not show any precipitation after storage for more than 2 months (insert of Figure 1D), suggesting excellent colloidal stability. Because of the intramolecular electron transfer from donor to acceptor upon excitation, neither PTA nor PTA-NPs displayed any significant fluorescence (Figure 1E), which was beneficial for heat generation via a nonradiative route.

\subsection{Reactive Oxygen Species (ROS) Generation}

As shown in Figure 1F, the probe of DCFH was oxidized to DCF by ROS generated from PTA-NPs upon $635 \mathrm{~nm}$ laser irradiation, and the fluorescence intensity of DCF increased linearly with time in the presence of PTA-NPs. In comparison, the probe of DCFH without PTA-NPs did not show any sign of fluorescence under the same conditions. Therefore, PTA-NPs upon laser irradiation could efficiently generate ROS for PDT applications.

\subsection{Photothermal Properties}

To evaluate the photothermal property of PTA-NPs, the temperature changes of PTANPs were recorded by a Flir-E6 thermal imager under $635 \mathrm{~nm}$ laser irradiation. First, the temperature elevation of PTA-NPs was recorded under laser irradiation of $635 \mathrm{~nm}$ at various laser power densities $\left(0.5,0.75,1.0,1.25\right.$, and $\left.1.5 \mathrm{~W} / \mathrm{cm}^{2}\right)$. Figure $2 \mathrm{~A}$ indicates that a higher laser power density resulted in a faster increase in the temperature of PTA-NPs. Moreover, the temperature enhancement of PTA-NPs exhibited concentration-dependent properties. As shown in Figure 2B, the temperature of PTA-NPs at the concentration of $45 \mu \mathrm{g} / \mathrm{mL}$ increased by $20^{\circ} \mathrm{C}$, while that at $135 \mu \mathrm{g} / \mathrm{mL}$ increased by $30{ }^{\circ} \mathrm{C}$ under $635 \mathrm{~nm}$ 
laser $\left(1.25 \mathrm{~W} / \mathrm{cm}^{2}\right)$ irradiation for $600 \mathrm{~s}$. In contrast, the temperature of DI water under the same conditions was not changed obviously. The excellent photostability of PTA-NPs was evaluated through five cycles of on/off laser irradiation $\left(635 \mathrm{~nm}, 1.25 \mathrm{~W} / \mathrm{cm}^{2}\right)$ without obvious variation (Figure 2C). The PCE of PTA-NPs was calculated according to the single irradiation circulation (Figure 2D). From the linear curve of cooling time $(t)$ vs. the negative natural logarithm of temperature $(-\ln \theta)$ (Figure $2 \mathrm{E})$, the time constant $\left(\tau_{\mathrm{s}}\right)$ was calculated to be $625 \mathrm{~s}$. With these data in hand, the PCE was calculated as $43 \%$ according to the Equation (1). Meanwhile, the photothermal images of PTA-NPs at different concentrations were visually recorded through a thermal infrared imager after laser irradiation for $10 \mathrm{~min}$ (Figure 2F). Therefore, PTA-NPs could be used a potential photothermal agent for cancer phototherapy.

A
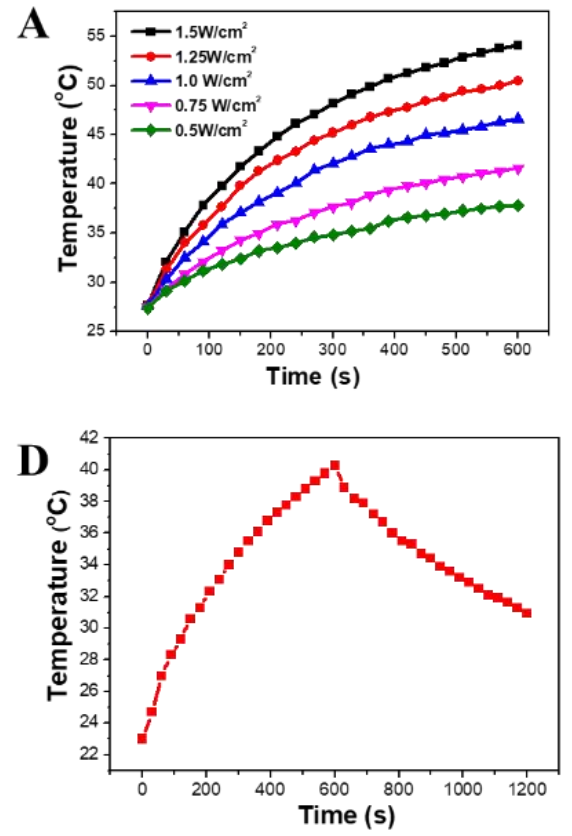
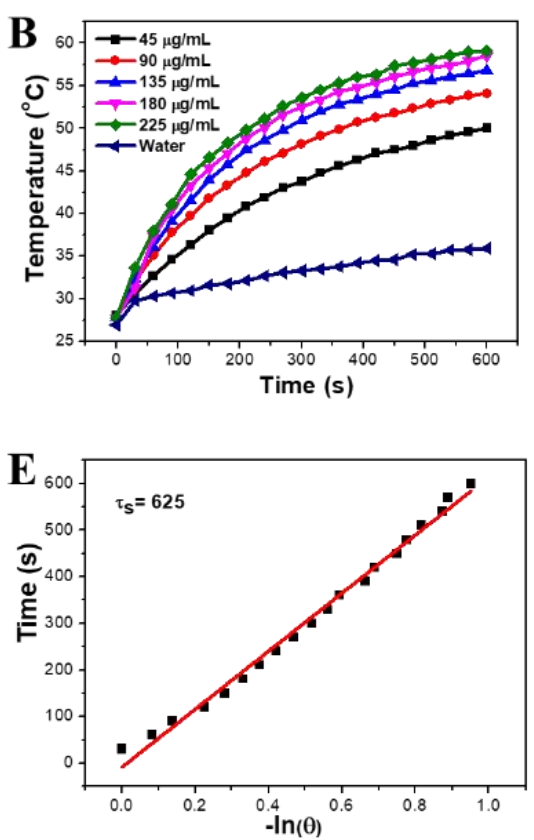

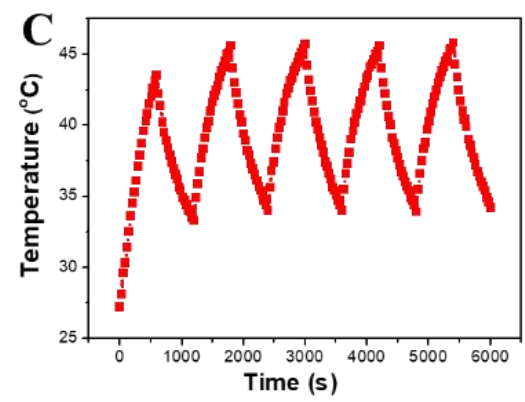

F

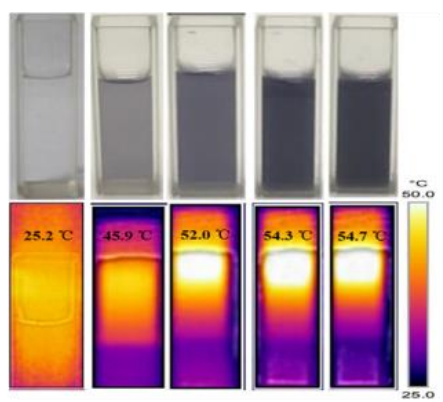

Figure 2. (A) Photothermal curves of PTA-NPs $(45 \mu \mathrm{g} / \mathrm{mL})$ under irradiation of $635 \mathrm{~nm}$ laser at different power densities; (B) photothermal curves of PTA-NPs at different concentration under $635 \mathrm{~nm}$ laser irradiation $\left(1.25 \mathrm{~W} / \mathrm{cm}^{2}\right)$; (C) photothermal stability of PTA-NPs $(45 \mu \mathrm{g} / \mathrm{mL})$ during five on/off cycles of laser $\left(1.25 \mathrm{~W} / \mathrm{cm}^{2}\right)$; (D) photothermal effect of PTA-NPs in water under irradiation of $635 \mathrm{~nm}$ laser $\left(1.25 \mathrm{~W} / \mathrm{cm}^{2}\right)$ for $10 \mathrm{~min}$, followed by the cooling for $10 \mathrm{~min}$; (E) negative logarithmic relationship between cooling time and temperature; $(\mathbf{F})$ photothermal images of different concentrations of PTA-NPs under $635 \mathrm{~nm}$ laser $\left(1.25 \mathrm{~W} / \mathrm{cm}^{2}\right)$ irradiation (top: images of PTA-NP solution under natural light; bottom: thermal images after $635 \mathrm{~nm}$ laser irradiation for $10 \mathrm{~min}$ ).

\subsection{MTT Assay}

The good biocompatibility of TPA-NPs was confirmed by MTT assay. As shown in Figure 3A, the viability of A549 cells was decreased to $78 \%$ with the concentration of TPA-NPs up to $20 \mu \mathrm{g} / \mathrm{mL}$ in the dark within $4 \mathrm{~h}$. It should be noted that a similar viability of A549 cells was observed in the dark within 24 or 96 h (Figure S7). The results indicate a relatively low toxicity against cancer cells under dark conditions. The reason for the decreased viability is probably ascribed to the fluctuation of temperature during the experiment, the activity of cells, and the humidity of the environment. Furthermore, some of the cells would have inevitably died naturally in the culture medium with the incubating time. In contrast, the viability of cancer cells incubated with $20 \mu \mathrm{g} / \mathrm{mL}$ TPANPs was reduced to $9.6 \%$ after laser irradiation $\left(635 \mathrm{~nm}, 1.5 \mathrm{~W} / \mathrm{cm}^{2}, 3 \mathrm{~min}\right)$. The half maximal inhibitory concentration $\left(\mathrm{IC}_{50}\right)$ of $6.5 \mu \mathrm{g} / \mathrm{mL}$ indicated the high photocytotoxicity of PTA-NPs under light irradiation. 
A

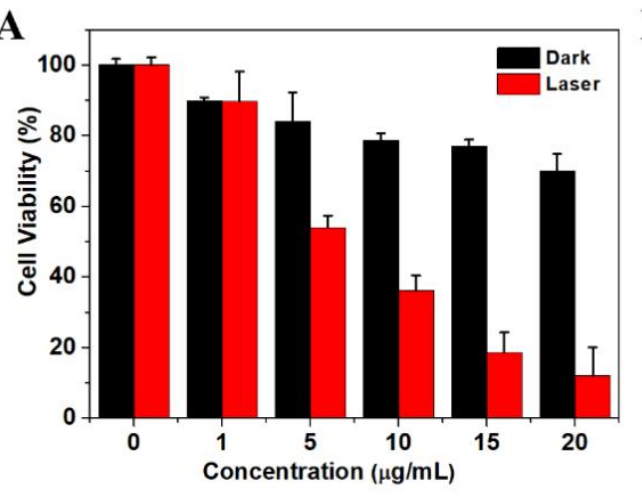

B

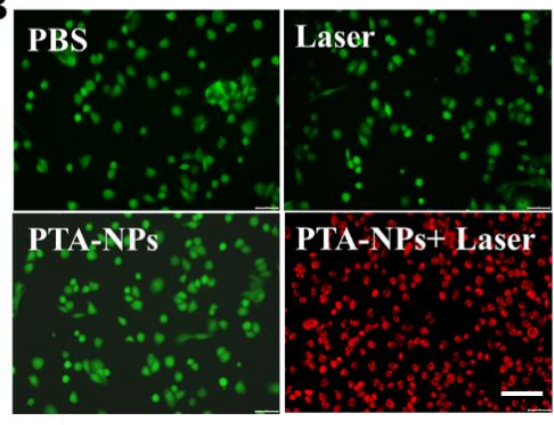

C

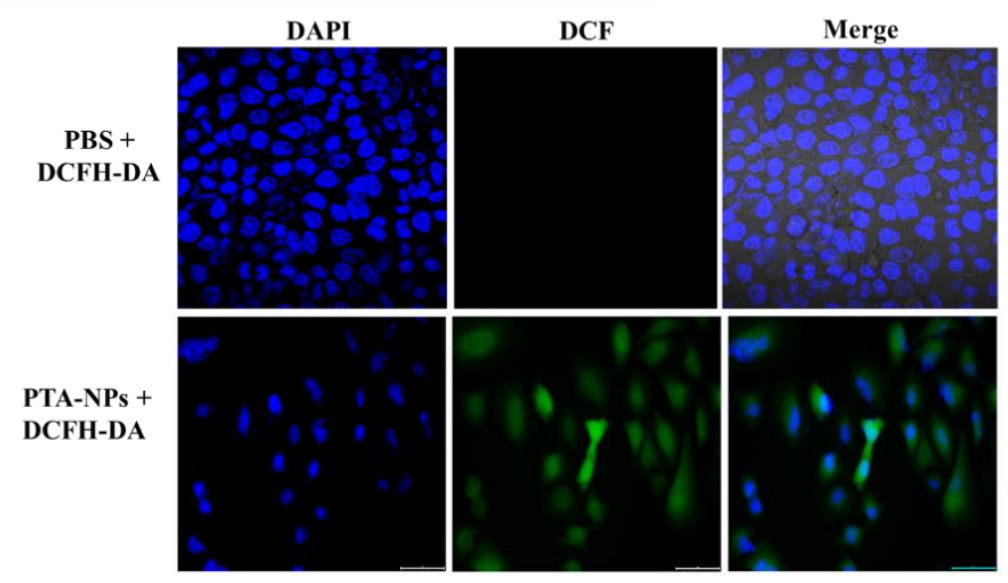

Figure 3. (A) Concentration dependence of the cytotoxicity of PTA-NPs against A549 cells; (B) fluorescence images of calcein AM (green fluorescence; live cells) and PI (red fluorescence; dead cells) co-stained A549 cells after treated with PBS only, laser irradiation only, PTA-NPs only, or PTA-NPs + laser irradiation (scale bar $=25 \mu \mathrm{m}$ ); (C) the intracellular ROS generation of PTA-NPs using DCFH-DA as a fluorescent probe (scale bar $=25 \mu \mathrm{m})$.

\subsection{Intracellular Co-Staining Assay}

The good biocompatibility and the photocytotoxicity of PTA-NPs were further verified in the live/dead cell co-staining test, where the live cells were stained with calcein AM (green fluorescence), while the dead cells were stained with propidium iodide (PI) (red fluorescence). As indicated in Figure 3B, the A549 cells treated with "PBS only", "laser irradiation only", or "PTA-NPs only" exhibited a green emission, indicating a negligible damage effect of bare PTA-NPs or laser irradiation alone. In contrast, the cancer cells showed a red emission after the treatment with PTA-NPs and $635 \mathrm{~nm}$ laser irradiation, suggesting that almost all of the cells were killed by the phototherapeutic effect of nanoagents.

\subsection{Intracellular ROS Generation}

HeLa cells incubated with PTA-NPs were investigated for intracellular ROS generation using DCFH-DA as a probe. A bright green emission was observed in the cytoplasm of A549 cells (Figure 3C) as a result of the ROS generation and the subsequent formation of green luminescent DCF. Thus, PTA-NPs could efficiently generate ROS in cancer cells under $635 \mathrm{~nm}$ laser irradiation.

\section{Conclusions}

In summary, organic nanoparticles (PTA-NPs) were prepared from a D-A-D structural organic molecule (PTA) through the nanoprecipitation method. PTA-NPs displayed good dispersibility and a uniform size in aqueous solution. The synergistic photother$\mathrm{mal} /$ photodynamic effects were demonstrated by the significant photothermal effect with PCE up to $43 \%$ and efficient ROS generation under $635 \mathrm{~nm}$ laser irradiation. The ROS 
generation of PTA-NPs in cancer cells was further evaluated using DCFH-DA as a probe. Lastly, the good biocompatibility and high photocytotoxicity of PTA-NPs were confirmed by MTT assay and a live/dead cell co-staining test. The results evidence that the asprepared PTA-NPs can be used as promising nanomaterials in synergistic photodynamic and photothermal cancer therapy.

Supplementary Materials: The following supporting information can be downloaded at: https: / / www.mdpi.com/article/10.3390/ma15020502/s1, Scheme S1: The synthetic routes of the intermediates 4 and 9 and precursors 7 and 10; Figure S1: The ${ }^{1}$ HNMR of structure 6; Figure S2: The ${ }^{1} \mathrm{HNMR}$ of structure 7 with the protection of trimethyl silica; Figure S3: The ${ }^{1} \mathrm{HNMR}$ of structure 10; Figure S4: The ESI-MS of structure 9; Figure S5: The ${ }^{1} \mathrm{HNMR}$ of PTA; Figure S6: The MALDI-TOF of PTA; Figure S7: The cell viability of A549 cells incubated with different concentrations of TPA-NPs for a period of 24 and $96 \mathrm{~h}$ in the dark.

Author Contributions: Conceptualization, F.W. and X.Z.; methodology, L.Y.; software, L.Y.; validation, L.Y., H.L. and Q.S.; formal analysis, L.Y.; investigation, L.Y., H.L. and Q.S.; resources, X.L.; data curation, X.L.; writing-original draft preparation, L.Y.; writing-review and editing, F.W.; visualization, X.Z.; supervision, F.W. and X.Z.; project administration, F.W.; funding acquisition, X.Z. All authors have read and agreed to the published version of the manuscript.

Funding: This work was supported by the National Natural Science Foundation of China (NSFC) (grant no. 21601142), the Key Project of Scientific Research Project of Hubei Provincial Department of Education (grant no. D20201504), and the Outstanding Young and Middle-aged Scientific Innovation Team of Colleges and Universities of Hubei Province: "Biomass chemical technologies and materials" (Grant No. T201908).

Institutional Review Board Statement: Not applicable.

Informed Consent Statement: Not applicable.

Data Availability Statement: The data presented in this study are available on request from the corresponding author.

Acknowledgments: Xunjin Zhu acknowledges the financial support from the Innovation and Technology Commission (UIM/373).

Conflicts of Interest: The authors declare no conflict of interest.

\section{References}

1. Felsher, D.W. Cancer revoked: Oncogenes as therapeutic targets. Nat. Rev. Cancer 2003, 3, 375-380. [CrossRef]

2. Chen, J.; Ding, J.; Xu, W.; Sun, T.; Xiao, H.; Zhuang, X.; Chen, X. Correction to Receptor and Microenvironment Dual-Recognizable Nanogel for Targeted Chemotherapy of Highly Metastatic Malignancy. Nano Lett. 2017, 17, 5180. [CrossRef] [PubMed]

3. Chen, Y.W.; Su, Y.L.; Hu, S.H.; Chen, S.Y. Functionalized graphene nanocomposites for enhancing photothermal therapy in tumor treatment. Adv. Drug Deliver. Rev. 2016, 105, 190-204. [CrossRef] [PubMed]

4. Sun, D.; Chen, J.; Wang, Y.; Ji, H.; Peng, R.Y.; Jin, L.B.; Wu, W. Advances in refunctionalization of erythrocyte-based nanomedicine for enhancing cancer-targeted drug delivery. Theranostics 2019, 9, 6885-6900. [CrossRef]

5. Cheng, L.; Wang, C.; Feng, L.; Yang, K.; Liu, Z. Functional nanomaterials for phototherapies of cancer. Chem. Rev. 2014, 114, 10869-10939. [CrossRef]

6. Wu, F.; Chen, J.; Li, Z.; Su, H.; Leung, K.; Wang, H.; Zhu, X. Red/Near-Infrared Emissive Metalloporphyrin-Based Nanodots for Magnetic Resonance Imaging-Guided Photodynamic Therapy In Vivo. Part. Part. Syst. Charact. 2018, 35, 1800208. [CrossRef]

7. Jiang, J.; Liu, D.; Zhao, Y.; Wu, F.; Yang, K.; Wang, K. Synthesis, DNA binding mode, singlet oxygen photogeneration and DNA photocleavage activity of ruthenium compounds with porphyrin-imidazo[4,5-f]phenanthroline conjugated ligand. Appl. Organomet. Chem. 2018, 32, e4468. [CrossRef]

8. Wu, F.; Su, H.; Cai, Y.; Wong, W.K.; Jiang, W. Porphyrin-Implanted Carbon Nanodots for Photoacoustic Imaging and in Vivo Breast Cancer Ablation. ACS Appl. Bio Mater. 2018, 1, 110-117. [CrossRef]

9. Cheng, X.; Sun, R.; Yin, L.; Chai, Z.; Shi, H.; Gao, M. Light-Triggered Assembly of Gold Nanoparticles for Photothermal Therapy and Photoacoustic Imaging of Tumors In Vivo. Adv. Mater. 2017, 29, 1604894. [CrossRef]

10. Feng, Z.; Guo, J.; Liu, X.; Song, H.; Wang, W. Cascade of reactive oxygen species generation by polyprodrug for combinational photodynamic therapy. Biomaterials 2020, 255, 120210. [CrossRef] 
11. Liu, Y.; Zhen, W.; Jin, L.; Zhang, S.; Sun, G.; Zhang, T.; Xu, X.; Song, S.; Wang, Y.; Liu, J. All-in-One Theranostic Nanoagent with Enhanced Reactive Oxygen Species Generation and Modulating Tumor Microenvironment Ability for Effective Tumor Eradication. ACS Nano 2018, 12, 4886-4893. [CrossRef]

12. Wang, W.; Wang, L.; Liu, S.; Xie, Z. Nanoscale Polymer Metal-Organic Framework Hybrids for Effective Photothermal Therapy of Colon Cancers. Adv. Mater. 2016, 28, 9320-9325. [CrossRef]

13. Yu, X.; Li, A.; Zhao, C.; Yang, K.; Chen, X.; Li, W. Ultrasmall Semimetal Nanoparticles of Bismuth for Dual-Modal Computed Tomography/Photoacoustic Imaging and Synergistic Thermoradiotherapy. ACS Nano 2017, 11, 3990. [CrossRef] [PubMed]

14. Jain, P.K.; Huang, X.H.; El-Sayed, I.H.; El-Sayed, M.A. Noble Metals on the Nanoscale: Optical and Photothermal Properties and Some Applications in Imaging, Sensing, Biology, and Medicine. Accounts Chem. Res. 2008, 41, 1578-1586. [CrossRef] [PubMed]

15. Gong, L.J.; Yan, L.; Zhou, R.Y.; Xie, J.N.; Wu, W.; Gu, Z.J. Two-dimensional transition metal dichalcogenide nanomaterials for combination cancer therapy. J. Mater. Chem. B 2017, 5, 1873-1895. [CrossRef]

16. Shibu, E.S.; Hamada, M.; Murase, N.; Biju, V. Nanomaterials formulations for photothermal and photodynamic therapy of cancer. J. Photochem. Photobiol. C 2013, 15, 53-72. [CrossRef]

17. Shen, S.; Wang, S.; Zheng, R.; Zhu, X.Y.; Jiang, X.G.; Fu, D.L.; Yang, W.L. Magnetic nanoparticle clusters for photothermal therapy with near-infrared irradiation. Biomaterials 2015, 39, 67-74. [CrossRef]

18. Zhou, J.; Lu, Z.; Zhu, X.; Wang, X.; Liao, Y.; Ma, Z.; Li, F. NIR photothermal therapy using polyaniline nanoparticles. Biomaterials 2013, 34, 9584-9592. [CrossRef]

19. Wu, F.; Chen, L.; Yue, L.; Wang, K.; Cheng, K.; Chen, J.; Luo, X.; Zhang, T. Small-Molecule Porphyrin-Based Organic Nanoparticles with Remarkable Photothermal Conversion Efficiency for in Vivo Photoacoustic Imaging and Photothermal Therapy. ACS Appl Mater. Interfaces 2019, 11, 21408-21416. [CrossRef] [PubMed]

20. Wang, L.; Qu, X.; Zhao, Y.; Weng, Y.; Zhou, S. Interfaces, Exploiting Single Atom Iron Centers in a Porphyrin-like MOF for Efficient Cancer Phototherapy. ACS Appl. Mater. Interfaces 2019, 11, 35228-35237. [CrossRef] [PubMed]

21. Du, L.; Qin, H.; Ma, T.; Zhang, T.; Xing, D. In Vivo Imaging-Guided Photothermal/Photoacoustic Synergistic Therapy with Bioorthogonal Metabolic Glycoengineering-Activated Tumor Targeting Nanoparticles. ACS Nano 2017, 11, 8930-8943. [CrossRef]

22. Wu, F.; Yue, L.; Cheng, K.; Chen, J.; Wong, K.L.; Wong, W.K.; Zhu, X. Facile Preparation of Phthalocyanine-Based Nanodots for Photoacoustic Imaging and Photothermal Cancer Therapy In Vivo. ACS Biomater. Sci. Eng. 2020, 6, 5230-5239. [CrossRef] [PubMed]

23. Yi, Z.; Wang, S.; Liu, Y. Design of High-Mobility Diketopyrrolopyrrole-Based $\pi$-Conjugated Copolymers for Organic Thin-Film Transistors. Adv. Mater. 2015, 27, 3589-3606. [CrossRef] [PubMed]

24. Jiang, X.; Wang, L.; Tang, H.; Cao, D.; Chen, W. Diketopyrrolopyrrole: An emerging phototherapy agent in fighting cancer. Dye. Pigment. 2020, 181, 108599. [CrossRef]

25. Cai, Y.; Liang, P.; Tang, Q.; Yang, X.; Si, W.; Huang, W.; Zhang, Q.; Dong, X. Diketopyrrolopyrrole-Triphenylamine Organic Nanoparticles as Multifunctional Reagents for Photoacoustic Imaging-Guided Photodynamic/Photothermal Synergistic Tumor Therapy. ACS Nano 2017, 11, 1054-1063. [CrossRef] [PubMed]

26. Li, X.; Kim, C.; Lee, S.; Lee, D.; Chung, H.M.; Kim, G. Nanostructured Phthalocyanine Assemblies with Protein-Driven Switchable Photoactivities for Biophotonic Imaging and Therapy. J. Am. Chem. Soc. 2017, 139, 10880-10886. [CrossRef]

27. Yao, Z.; Yan, C.; Zhang, M.; Li, R.; Cai, Y.; Wang, P. N-Annulated Perylene as a Coplanar $\pi$-Linker Alternative to Benzene as a Low Energy-Gap, Metal-Free Dye in Sensitized Solar Cells. Adv. Energy Mater. 2014, 4, 1400244. [CrossRef]

28. Fan, Q.; Cheng, K.; Yang, Z.; Zhang, R.; Yang, M.; Hu, X.; Ma, X.; Bu, L.; Lu, X.; Xiong, X.; et al. Perylene-diimide-based nanoparticles as highly efficient photoacoustic agents for deep brain tumor imaging in living mice. Adv. Mater. 2015, $27,843-847$. [CrossRef]

29. Liu, Y.; Bhattarai, P.; Dai, Z.; Chen, X. Photothermal therapy and photoacoustic imaging via nanotheranostics in fighting cancer. Chem Soc. Rev. 2019, 48, 2053-2108. [CrossRef]

30. Zhang, S.; Guo, W.; Wei, J.; Li, C.; Liang, X.J.; Yin, M. Terrylenediimide-Based Intrinsic Theranostic Nanomedicines with High Photothermal Conversion Efficiency for Photoacoustic Imaging-Guided Cancer Therapy. ACS Nano 2017, 11, $3797-3805$. [CrossRef]

31. Zhang, S.B.; Li, J.H.; Wei, J.; Yin, M.Z. Perylenediimide chromophore as an efficient photothermal agent for cancer therapy. Sci. Bull. 2018, 63, 101-107. [CrossRef]

32. Ding, K.K.; Zhang, Y.W.; Si, W.L.; Zhong, X.M.; Cai, Y.; Zou, J.H.; Shao, J.J.; Yang, Z.; Dong, X.C. Zinc(II) Metalated Porphyrins as Photothermogenic Photosensitizers for Cancer Photodynamic/Photothermal Synergistic Therapy. ACS Appl. Mater. Interfaces 2018, 10, 238-247. [CrossRef] [PubMed]

33. Jiang, Z.Y.; Zhang, C.L.; Wang, X.Q.; Yan, M.; Ling, Z.X.; Chen, Y.C.; Liu, Z.P. A Borondifluoride-Complex-Based Photothermal Agent with an $80 \%$ Photothermal Conversion Efficiency for Photothermal Therapy in the NIR-II Window. Angew. Chem. Int. Ed. 2021, 60, 22376-22384. [CrossRef]

34. Gao, H.Q.; Zhang, L.R.; Lian, X.L.; Wang, Y.; Jiang, S.H.; Wang, G.H.; Dai, X.H.; Zou, H.R.; Ding, D. A dentin hypersensitivity treatment using highly stable photothermal conversion nanoparticles. Mat. Chem. Front. 2021, 5, 3388-3395. [CrossRef]

35. Huang, H.; Che, Y.; Zang, L. Direct synthesis of highly pure perylene tetracarboxylic monoimide. Tetrahedron. Lett. 2010, 51, 6651-6653. [CrossRef] 
36. Rajavelu, K.; Rajakumar, P.; Sudip, M.; Kothandaraman, R. Synthesis, photophysical, electrochemical, and DSSC application of novel donor-acceptor triazole bridged dendrimers with a triphenylamine core and benzoheterazole as a surface unit. New J. Chem. 2016, 40, 10246-10258. [CrossRef]

37. Mba, M.; D’Acunzo, M.; Salice, P.; Carofiglio, T.; Maggini, M.; Caramori, S.; Campana, A.; Aliprandi, A.; Argazzi, R.; Carli, S.; et al. Sensitization of Nanocrystalline TiO2 with Multibranched Organic Dyes and Co(III)/(II) Mediators: Strategies to Improve Charge Collection Efficiency. J. Phys. Chem. C 2013, 117, 19885-19896. [CrossRef]

38. Mahmood, Z.; Xu, K.; Küçüköz, B.L.; Cui, X.; Zhao, J.; Wang, Z.; Karatay, A.; Yaglioglu, H.G.; Hayvali, M.; Elmali, A. DiiodoBodipyPerylenebisimide Dyad/Triad: Preparation and Study of the Intramolecular and Intermolecular Electron/Energy Transfer. J. Org. Chem. 2015, 80, 3036-3049. [CrossRef] [PubMed]

39. Chen, L.; Liu, D.; Wu, M.; Chau, H.F.; Wang, K.; Fung, Y.H.; Wong, K.L.; Wang, Z.; Wu, F. Photodynamic and photothermal synergistic behavior of triphenylamine-porphyrin nanoparticles for DNA interaction, cellular cytotoxicity and localization Nanotechnology 2020, 31, 315101. [CrossRef]

40. Zhang, J.; Yang, C.; Zhang, R.; Chen, R.; Zhang, Z.; Zhang, W.; Peng, S.H.; Chen, X.; Liu, G.; Hsu, C.S.; et al. Biocompatible D-A Semiconducting Polymer Nanoparticle with Light-Harvesting Unit for Highly Effective Photoacoustic Imaging Guided Photothermal Therapy. Adv. Funct. Mater. 2017, 27, 1605094. [CrossRef] [PubMed]

41. Yue, L.; Li, H.; Sun, Q.; Zhang, J.; Luo, X.; Wu, F.; Zhu, X. Red-Emissive Ruthenium-Containing Carbon Dots for Bioimaging and Photodynamic Cancer Therapy. ACS Appl. Nano Mater. 2020, 3, 869-876. [CrossRef]

42. Li, H.; Yue, L.; Wu, M.; Wu, F. Self-assembly of methylene violet-conjugated perylene diimide with photodynamic/photothermal properties for DNA photocleavage and cancer treatment. Colloids Surf. B 2020, 196, 111351. [CrossRef] [PubMed] 